\title{
Substituting meat and the role of a situational context: exploring associations and motives of Dutch meat substitute-users
}

\author{
Johanna E. Elzerman
}

Department of Agrotechnology and Food Sciences,

Wageningen University and Research, Wageningen, The Netherlands and Department of Food Technology, Van Hall Larenstein University of Applied Sciences, Velp, The Netherlands, and

\author{
Pieke E.M. van Dijk and Pieternel A. Luning \\ Department of Agrotechnology and Food Sciences, \\ Wageningen University and Research, Wageningen, The Netherlands
}

\begin{abstract}
Purpose - The Dutch market for meat substitutes has grown steadily, however, their market share is still low, and meat consumption in the Netherlands is not decreasing. For a transition towards a more plant-based diet, understanding consumer motives regarding meat substitutes is important. The purpose of this study was to explore what motives lay behind the appropriateness of the use of meat substitutes in different usage situations.

Design/methodology/approach - In total, 20 semi-structured in-depth interviews were performed to discover Dutch consumers' associations with the terms "eating vegetarian" and "meat substitutes", as well as motives regarding the situational appropriateness of meat substitutes.

Findings - The most mentioned motives for eating vegetarian were "environmental impact", "health" and "animal welfare", while meat substitutes were mainly eaten to replace meat in the meal. Most participants perceived vegetarian stir-fry pieces appropriate for almost all situations; the appropriateness of other meat substitutes was more situation-specific. The thematic content analysis yielded seven categories for the motives given for the (in)appropriateness of the four meat substitutes in six usage situations: "Functionality", "Convenience", "Properties", "Preferences", "Association with meat", "Association with meals" and "Nutrition". Mainly motives in the categories convenience and functionality (function of the meat substitute in a meal) were mentioned for all situations and other motives were situation-specific.

Originality/value - The focus in the development of plant-based foods is mostly on the product properties. The situational appropriateness and the underlying motives regarding meat substitutes have not yet been studied. This exploratory study suggests that these should be taken into consideration in the design of new meat substitutes.
\end{abstract}

Keywords Meat substitute, Meat, Sustainability, Situational context, Consumer acceptance,

In-depth interviews, Motives

Paper type Research paper

(C) Johanna E. Elzerman, Pieke E.M. van Dijk and Pieternel A. Luning. Published by Emerald Publishing Limited. This article is published under the Creative Commons Attribution (CC BY 4.0) licence. Anyone may reproduce, distribute, translate and create derivative works of this article (for both commercial and non-commercial purposes), subject to full attribution to the original publication and authors. The full terms of this licence may be seen at http://creativecommons.org/licences/by/4.0/legalcode

The authors would like to thank the interviewees for their participation in the study, as well as Professor MAJS van Boekel and the reviewers for their helpful comments on the manuscript.

Received 24 September 2021 Revised 9 December 2021 23 January 2022

Accepted 23 January 2022 
$\mathrm{BFJ}$

124,13

\section{Introduction}

Numerous studies underline the importance of a "protein transition", i.e. the shift away from the consumption of animal proteins, such as meat and dairy, towards vegetable and new protein sources (e.g. Aiking, 2011; Smil, 2002; Tijhuis et al., 2011; Van der Weele et al., 2019). The EAT-Lancet Commission on healthy diets and sustainable food systems advises a flexitarian diet, which is largely plant-based, but that can include modest amounts of meat, fish and dairy (Willett et al., 2019). To achieve this, consumers do not all have to become vegetarians, but the reduction of meat consumption several days a week by increasing fruit, vegetable and other plant-based food consumption could be a start to achieving these goals.

Meat substitutes, products that strive to resemble the (sensory) properties of meat, could facilitate this transition, mainly to win over consumers who are used to eating meat on a daily basis (Elzerman et al., 2011; Hoek et al., 2011a). These products have been widely available in Dutch supermarkets for the last 30 years and their market share is growing steadily (de Waard, 2021; IRI Nederland, 2021). However, meat consumption in the Netherlands is not decreasing (Dagevos et al.,2020). Therefore, consumer researchers try to understand what are the important factors in the preference for meat and the acceptance of meat substitutes (e.g. Hoek et al., 2011a; Michel et al., 2021). First, not all consumers seem to see the need to substitute meat (Elzerman et al., 2013), and the habit of eating meat seems to be a barrier in the acceptance of meat substitutes (De Bakker and Dagevos, 2010). Consumers' drivers and barriers regarding the use of meat substitutes can be related to the sensory appeal, habits, familiarity, health, environmental factors and concerns about the preparation of meat substitutes (Hoek et al., 2011a; Onwezen et al., 2021; Tso et al., 2021). Also, eating meat has been reported to be associated with maleness (Weinrich, 2018). Furthermore, the sensory properties of meat substitutes, such as texture, have been an issue in the acceptance, although these have improved over the years (e.g. Fiorentini et al., 2020). Another factor can be that consumers sometimes seem to need some time to get used to new products; some meat substitutes were better liked after repeated exposure (Hoek et al., 2013). Other factors, like promotion and word of mouth influence how familiar a new product, becomes and how many consumers are willing to taste it. After rejection, it can take a lot of time before consumers are willing to try a new product again (Horvat et al., 2020).

Besides preferences, factors such as habits and beliefs about meat and meat substitutes, social norms on what foods are safe and appropriate to eat, affect food choice as well (Higgs, 2015). Normative eating behaviour, such as the judgement of the appropriateness of foods in a situational context appears to be important in food acceptance (Schutz, 1988; Hersleth et al., 2015; Giacalone and Jaeger, 2019). A recent consumer survey on the situational appropriateness of meat substitutes investigated how meat products and their vegetarian counterparts matched with different usage situations (Elzerman et al., 2021). That study showed that, overall, meat products were rated as more appropriate than meat substitutes in almost all usage situations and that different situations received different appropriateness ratings. However, the why behind the situational appropriateness of meat substitutes remained unclear.

The main research question of this paper is what drives consumers of meat substitutes to use a meat substitute in a particular usage situation? The study could contribute to the insight into how consumer preferences regarding meat substitutes come into being. Furthermore, this information can be applied to develop meat substitutes that fit better in consumers' daily lives.

The objectives of this study are:

(1) To gain insight into associations that Dutch meat substitute-users have with meat substitutes and eating vegetarian. 
(2) To find out typical motives behind the consideration of whether a meat substitute is (in)appropriate in a particular usage situation.
Use of meat substitutes

\section{Materials and methods}

\subsection{Meat substitutes and usage situations}

Four meat substitutes that are available on the Dutch market were selected: vegetarian minced meat, vegetarian hamburger, vegetarian steak and vegetarian stir-fry pieces (vegan chicken-like strips). These products are commonly used meat substitutes, except for vegetarian steak. The vegetarian steak was used as it was a newer product that is the vegetarian counterpart of a more luxurious meat product (steak) and therefore might give different results compared to the other products. No brand names or ingredients were given since we were interested in consumer response to the product type and not the specific products. The products were presented to the participants as a photograph in a transparent container without the brand package and without the plastic foil that is used for keeping the plastic container closed (as depicted in Figure 2 for stir-fry pieces and vegetarian steak and the appendix for vegetarian mince and vegetarian hamburger).

Six usage situations were selected from the nine situations that were part of a previous survey (Elzerman et al., 2021). The usage situations were phrased as follows:

Usage situation

"When I eat with my family/household"

"When I want to prepare a special meal"

"When I eat alone"

"When I want to add flavour to the meal"

"When I have little time to cook"

"When I want to eat a healthy meal"
Abbreviated in figures as

Family

Special

Alone

Flavour

Time scarcity

Healthy

\subsection{In-depth interviews}

The in-depth interviews consisted of two types of questions: association questions and questions of the situational appropriateness of specific meat substitutes. With the association questions, the participant was asked to mention his/her associations with the words "eating vegetarian" and "meat substitutes". In these two first questions, no reference was made to any meat substitute nor definition of meat substitutes was given; the associations were simply based on the participant's own experiences.

The appropriateness questions started with a brief introduction of each usage situation to familiarize the participant with the concept of usage situations. The meat substitutes were accompanied by a photograph of the specific meat substitute, with a generic product name and no further description or brand name. After introducing the meat substitutes and usage situations, questions regarding the appropriateness of the products in each usage situation were asked, e.g. "Which of these products do you consider to be appropriate in this situation?" and "What are your reasons for this consideration?" Some different follow-up questions per participant were asked for more clarification of certain answers.

The in-depth interviews were held and recorded via the Microsoft Teams video call program in December 2020 and January 2021 and lasted around 30 min each. The screen of the interviewer was shared showing a PowerPoint Presentation with the interview questions and the different meat substitutes. 
BFJ

124,13

\subsection{Participant recruitment}

This study was approved by the Social Sciences Ethics Committee of Wageningen University. For this explorative study, we aimed for a diverse group of Dutch participants, in terms of age, gender and dietary habits. A promotional flyer with a brief description of the study was sent to consumers who had participated in a previous survey and had indicated that they were willing to participate in future research. The response rate was $29.4 \%$ and the 20 recruited participants ( 3 males and 17 females) were between 20 and 74 years old (mean age 42.25 years) and were selected because they were all users of meat substitutes. Their usage frequency of meat substitutes during the hot meal varied between less than once a month and 1-2 times per week. Non-users did not participate in this study, since they do not have experience with meat substitutes, so it is difficult to motivate the appropriateness of these products in usage situations. Both vegetarian and non-vegetarian respondents were part of this study, to obtain diverse perspectives on meat substitutes and to cover the range of possible motives. Demographic and consumption data of the participants are summarized in Appendix 1. After the study, the participants received a gift card for their participation in the interview.

Moreover, the number of interviews needed was determined based on the degree of data saturation, i.e. the point at which no new information or themes are observed in the data (Guest et al., 2006). In this study, after evaluating the 20 interviews, it became clear that data saturation was reached after 16 interviews.

\subsection{Data analysis}

This research used a thematic content analysis approach to analyse all the data that resulted from the in-depth interviews based on the qualitative data analysis described by Zanin et al. (2021). The data analysis started with transcribing the verbal data of the recordings from the in-depth interviews. The transcripts of the interviews (raw data) were carefully read and sections of answers, that answered an interview question, were grouped. After categorizing the answers of all the transcripts, units of analysis were selected. Next, the whole context of these units of analysis (i.e. sentences before/after the units of analysis that gave meaning to the units of analysis) was noted, which were called context units. All context units were compared and, if possible, grouped when they had the same meaning. A core of meaning was assigned to these grouped context units. As cores of meaning could be related to each other, they were further grouped into different categories. The frequency with which motives in a category were mentioned were counted for every usage situation, and if a participant mentioned a motive just for one of the products, it was counted as 1 , but if the participant specifically mentioned that this motive also applied to the other products, the motive was counted again. MAXQDA 2020 (VERBI Software, 2019) was used to further analyse and visualize the data. The second author performed the data analysis, and the first author checked and agreed on the classification of all context units into cores of meaning and categories. The choice of relevant quotes was discussed among the authors. This was done to improve the reliability of the data.

\section{Results}

\subsection{Associations with "eating vegetarian" and "meat substitutes"}

To get insight into how the product category of meat substitutes was perceived, respondents were asked to give their associations with the terms "eating vegetarian" and "meat substitutes".

Figure 1a shows the associations of the participants with "eating vegetarian". The participants often mentioned product-related properties, such as "no meat", "alternative protein products" and "meat substitutes", as illustrated in the following quote: 


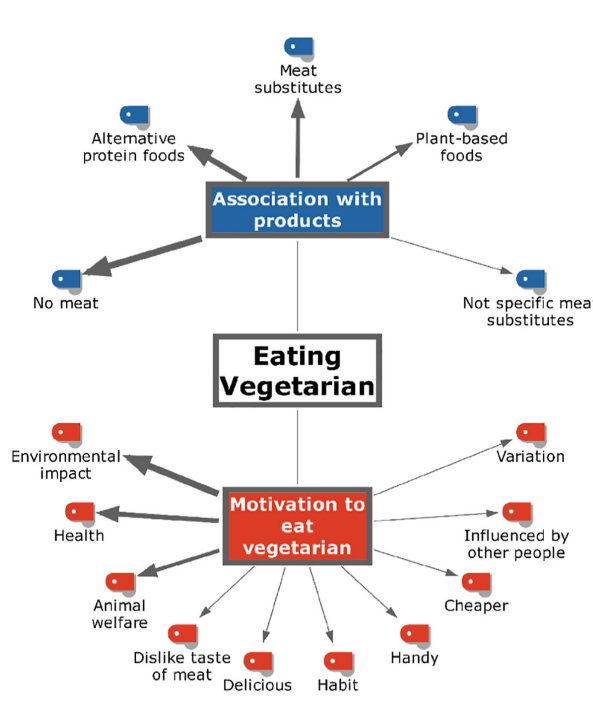

(a)

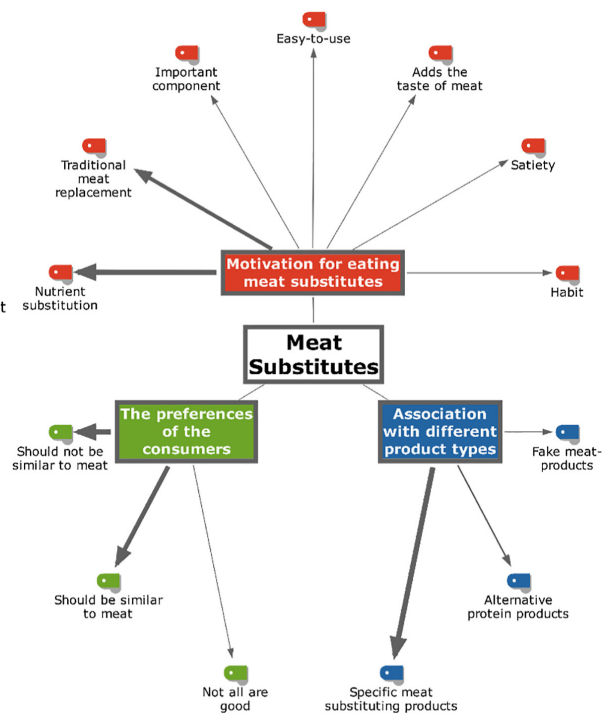

(b)

Note(s): A thicker arrow means that an association is mentioned more frequently

I think about a meal without any meat or fish. This can be prepared with or without substituting the meat. So, just a meal without meat. [participant 11]

This question also elicited reasons for eating a vegetarian meal or diet, such as the environmental impact of meat consumption, health reasons and animal welfare, as demonstrated in the following quote:

We are doing this, because: (A) we think a lot of meat is not healthy, and (B) it is better for the world if everyone eats less meat from intensive animal farming. [participant 6]

Figure $1 \mathrm{~b}$ shows the associations of the participants with the term "meat substitutes". The participants either related "meat substitutes" with different product types or gave arguments for eating meat substitutes. Moreover, the participants often mentioned specific meat substitutes, as stated in the quote below:

Nowadays, there are a lot of meat substitutes, such as vegetarian minced meat, but there are also vegetarian chicken pieces that can be used in all kinds of dishes. [participant 10]

When participants gave motives for eating "meat substitutes" it was often related to "nutrient source", followed by "traditional meat replacement" (see Figure 1b). As demonstrated in the quote below.

I think it can yet be a way of taking in proteins. Especially when you eat a traditional meal with "potatoes, vegetables, and meat". Without the meat, it is not complete. If you then add a meat substitute, I think you will still receive some of the nutrients that are usually in meat. [participant 5]

When participants expressed their associations with "meat substitutes", it was often mentioned that meat substitutes should not be similar to meat products (see Figure $1 \mathrm{~b}$ ), although other participants reasoned that meat substitutes should be similar to meat products. These two different opinions are reflected in the following quotes: 
BFJ

124,13

\section{8}

Number of participants that indicated a meat substitute to be appropriate in a usage situation $(n=20)$
We have been vegetarians for such a long time now that we prefer meat substitutes that do not look and taste like meat. Appearance is not that important, but I do think that the nutritional value should be close to that of meat. [participant 3]

If you want your meal to have a certain mouthfeel, then it is important that meat substitutes are almost similar to meat. [participant 19]

\subsection{Perceived appropriateness of meat substitutes in different usage situations}

In the next step of the interviews, the participants were asked to indicate per usage situation, which meat substitutes they found appropriate. Table 1 presents how many participants indicated the appropriateness of the four different meat substitutes in the six different usage situations. Most of the participants expressed vegetarian stir-fry pieces and vegetarian mince to be appropriate in almost every usage situation except for the usage situation "cooking a special meal". Almost all (19) respondents indicated vegetarian hamburgers to be appropriate in the situation when cooking with time scarcity. The vegetarian steak was mentioned as appropriate by the smallest number of respondents for every situation, except for "cooking a special meal". In this situation, 7 of the 20 respondents found the use of vegetarian steak to be appropriate.

\subsection{Motives for the (in) appropriateness of meat substitutes in different usage situations}

To get insight into reasons behind why meat substitutes are (in)appropriate in a usage situation, respondents were asked to mention motives of why they would or would not use a meat substitute in a particular situation. The thematic content analysis yielded in total seven categories of motives, as shown and defined in Table 2. The motives were categorized into "Functionality", "Convenience", "Properties", "Preferences", "Association with meat", "Association with meals" and "Nutrition". Depending on the usage situation, participants gave different types of motives, e.g. the usage situations "when I have little time to cook" and "when I want to cook a special meal" yielded mainly motives that were associated with the duration of particular types of meals, while motives in the category "Nutrition" were mainly mentioned for the situation "when I want to cook a healthy meal" and occasionally for the situation "when I eat with my family/household". Most motives that were mentioned fell in the category "Functionality" and were about the role that the meat substitute has in a meal, such as "product completes the meal", "product does (not) blend well with other ingredients" or "product does not give added value to the meal".

Other motives that were mentioned by many participants regarded the association that they had with particular types of meals, product properties and the convenience of the

\begin{tabular}{|c|c|c|c|c|}
\hline \multirow[b]{2}{*}{ Usage situation } & \multicolumn{4}{|c|}{ Meat substitute } \\
\hline & $\begin{array}{l}\text { Vegetarian stir-fry } \\
\text { pieces }\end{array}$ & $\begin{array}{l}\text { Vegetarian } \\
\text { mince }\end{array}$ & $\begin{array}{l}\text { Vegetarian } \\
\text { hamburger }\end{array}$ & $\begin{array}{l}\text { Vegetarian } \\
\text { steak }\end{array}$ \\
\hline Eating alone & 11 & 10 & 16 & 8 \\
\hline $\begin{array}{l}\text { Eating with family/ } \\
\text { household }\end{array}$ & 17 & 19 & 13 & 8 \\
\hline Cooking a healthy meal & 14 & 10 & 8 & 7 \\
\hline $\begin{array}{l}\text { Cooking with time } \\
\text { scarcity }\end{array}$ & 18 & 16 & 19 & 11 \\
\hline $\begin{array}{l}\text { To add flavour to the } \\
\text { meal }\end{array}$ & 12 & 10 & 10 & 7 \\
\hline Cooking a special meal & 8 & 4 & 4 & 7 \\
\hline
\end{tabular}




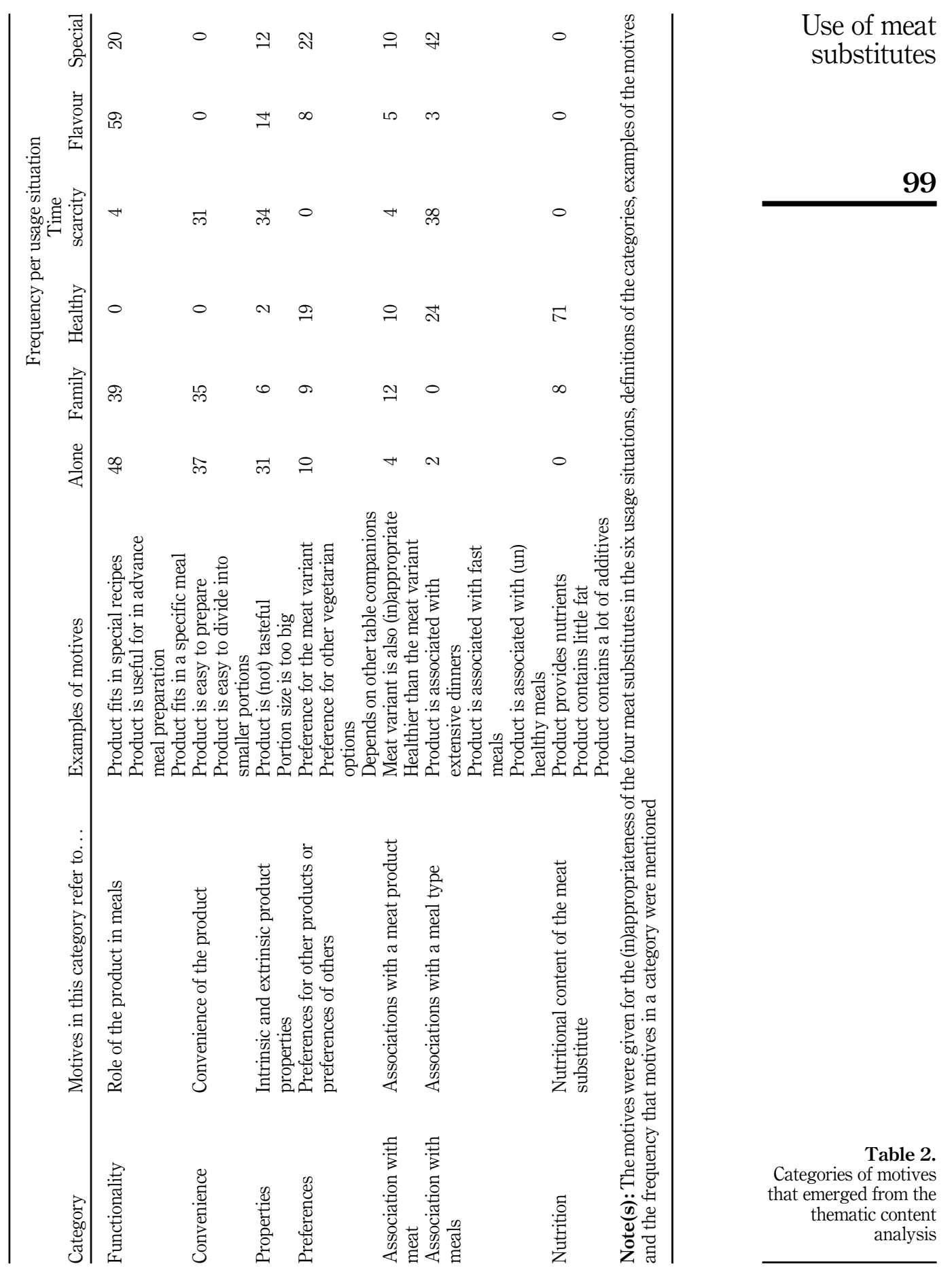


BFJ

124,13

product. Many participants mentioned motives in the category "Convenience" for all four meat substitutes (e.g. "easy to prepare", "almost ready to eat", and "easy to divide into smaller portions"). These motives were mentioned for the situations "when I have little time to cook", "when I eat alone", and "when I eat with my family/household".

Meat substitutes were not often related to their meat counterparts; participants gave fewer motives that were related to meat (products), such as that the meat counterpart was more or less appropriate or healthier.

Some participants explained the inappropriateness of a meat substitute in a situation by mentioning their preferences for other meal components, such as meat, vegetables or other meat substitutes.

Figure 2 shows the most mentioned motives for the (in)appropriateness for vegetarian steak and stir-fry pieces in the six usage situations. The motives for vegetarian hamburgers and mince are shown in the supplementary material since they were somewhat similar to those for vegetarian steak and stir-fry pieces respectively. Zooming into the four different meat substitutes, several similarities and differences stand out. Vegetarian stir-fry pieces and mince overall received more positive motives than vegetarian steak and hamburger. Also, the most mentioned motives for every usage situation were mostly positive for stir-fry pieces and mince, while vegetarian steak mainly received more negative motives for the situation "when I want to cook a healthy meal".

Most positive motives were about the fast and easy preparation of the product, suitability for specific recipes, and healthiness of the products, whereas most negative motives were about the taste, the unhealthiness and the association that meat substitutes are not suitable for a special occasion.

Vegetarian stir-fry pieces, vegetarian mince and vegetarian hamburgers were often associated with a quick meal, whereas vegetarian steak was more often associated with an extensive dinner.

\section{Discussion}

This exploratory study investigated what drives consumers of meat substitutes to use a meat substitute in a particular usage situation. The associations with the terms "eating vegetarian" and "meat substitutes" were identified and consumers' underlying motives behind the perceived situational appropriateness of four different meat substitutes in six different situations were assessed. Our findings show that the respondents associated "eating vegetarian" mainly with the omission of meat, and with the reasons behind this, such as environmental impact. Consumer awareness of the large environmental impact of meat seems low and therefore environmental reasons do not seem to be a major motive for reducing meat intake in the Western population (Sanchez-Sabate and Sabaté, 2019; Hartmann and Siegrist, 2017). However, Vanloo et al. (2017) found consumer segments, based on the involvement in sustainable eating; the more involved consumers had a more plantbased diet. In the current study, the participants were all users of meat substitutes, some of them were vegetarian. Vegetarians are more likely to agree that meat production is bad for the environment (Mullee et al., 2017). "Health" and "animal welfare" were also often associated with "eating vegetarian" in our study. Several other studies also showed that health considerations and animal welfare were motives for people to become vegetarian or reduce meat consumption (Sanchez-Sabate and Sabaté, 2019; Hartmann and Siegrist, 2017; De Boer and Aiking, 2017; Mullee et al., 2017). Furthermore, a need for variety and the interest in new tastes and new foods were illustrated as drivers for considering a more vegetarian diet for light to medium meat-eating consumers (Mullee et al., 2017; Hoek et al., 2011a). Variation was only mentioned by a few participants in the present study and to discover new tastes was not mentioned at all. 


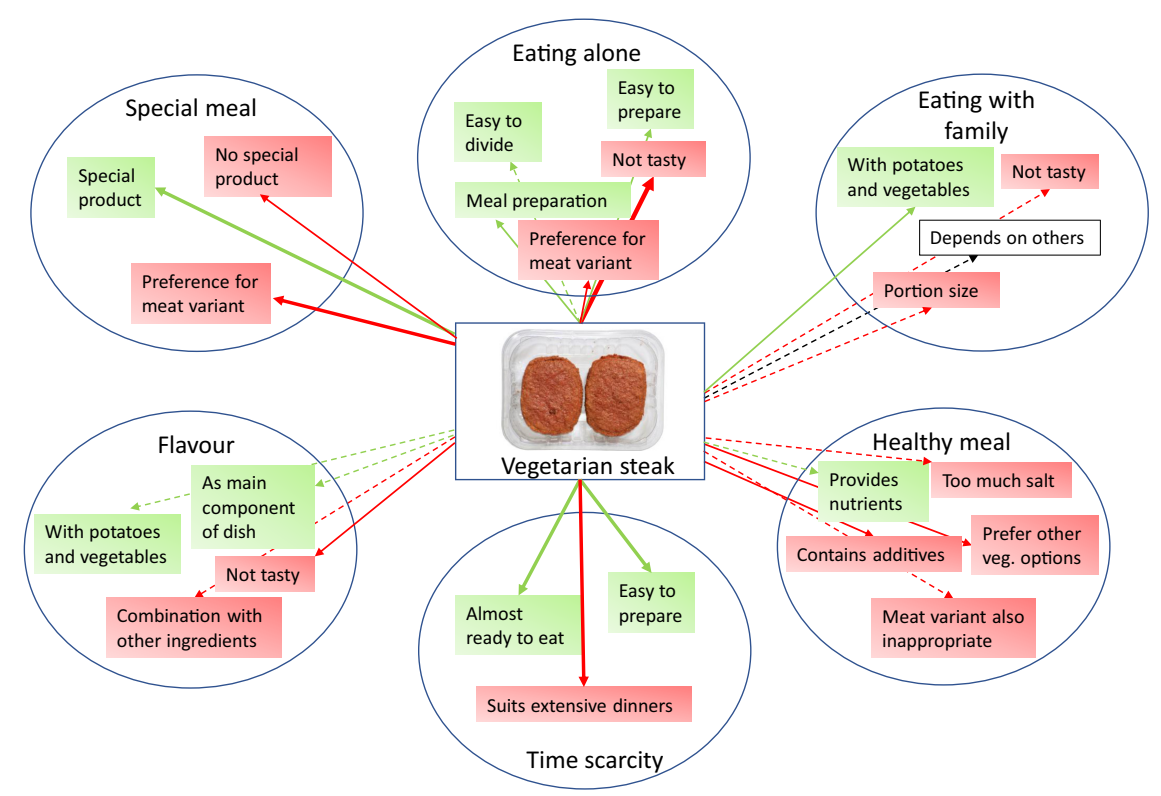

Use of meat substitutes

(a)

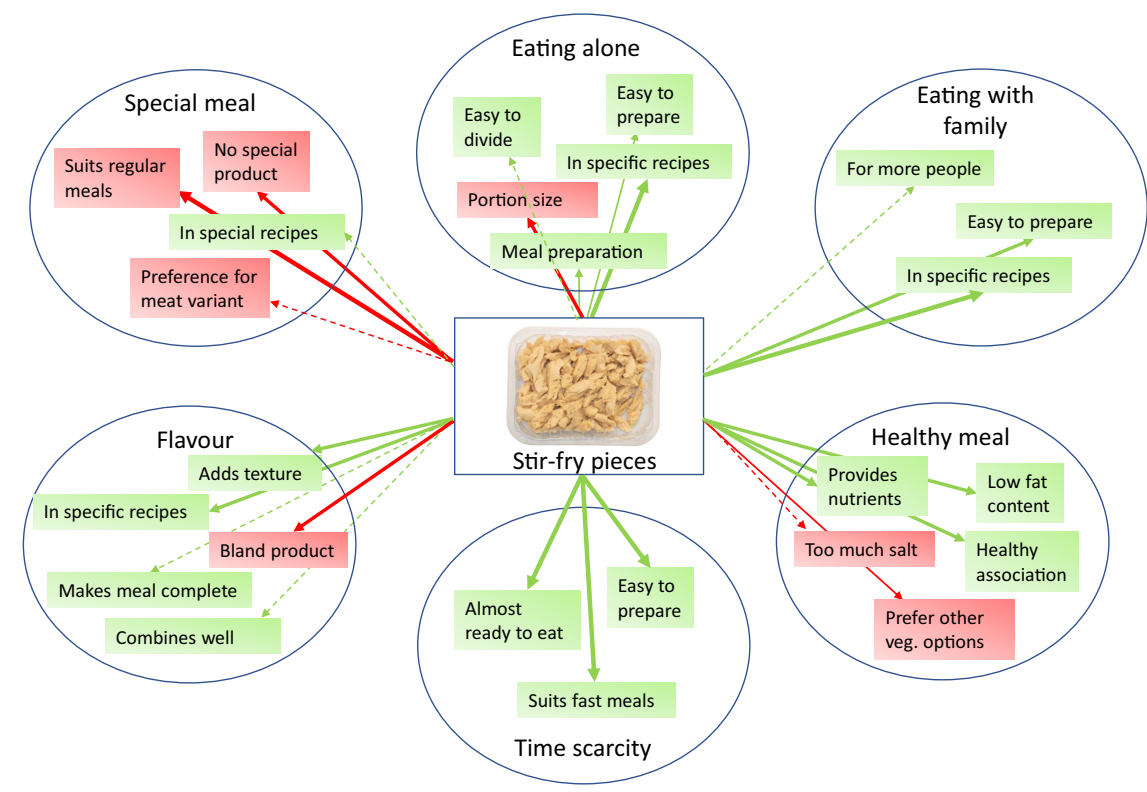

(b)

Note(s): Motives that are included in the figures were mentioned by at least three participants for a situation and the thicker the arrow, the more often a motive was mentioned

Figure 2. Motives for the appropriateness (green) or inappropriateness (red) of the use of vegetarian steak (2a) and vegetarian stir-fry pieces $(2 \mathrm{~b})$ in the six usage situations, as mentioned in the indepth interviews $(n=20)$ 
$\mathrm{BFJ}$

124,13

102
The term "meat substitutes" evoked different associations: some respondents mentioned that meat substitutes should be similar to meat, whereas others preferred products to be dissimilar to meat. This was also found in previous focus group discussions; some consumers mentioned that they would rather buy meat substitutes that resembled meat as it was easier to prepare a dish with them, whereas others brought forward that meat substitutes needed to have an identity of their own (Elzerman et al., 2013). In another study, heavy users of meat substitutes tended to prefer sensory properties that are dissimilar to meat, possibly because these consumers often have a predominantly vegetarian lifestyle (Hoek et al., 2011a). On the other hand, low users of meat alternatives preferred meat-like products (Michel et al., 2021). Hoek et al. (2011b) pointed out that unfamiliarity with meat substitutes was a key barrier for non-users and light-to-medium users, which might explain why some participants in the current research preferred meat substitutes to be similar to meat. "Nutrient substitution", the substitution of proteins or other nutrients which was normally provided by meat, was also often mentioned as an association with "meat substitutes" which is in line with previous research (Elzerman et al., 2013). Likewise, health and nutritional quality were shown to be important drivers in consumer interest in alternative proteins (Tso et al., 2021).

To find out typical motives behind the consideration of whether a meat substitute is (in) appropriate in a particular usage situation, the interviews were set up to direct participants to think about how they would behave when cooking a meal with the meat substitute and how they envisioned it to be part of that meal. Our study discovered that motives can be grouped into different categories. These categories were inductively identified from the qualitative information from the interviews and underlined what type of information participants shared to substantiate the appropriateness of meat substitutes in usage situations. Participants mainly gave motives and associations that had to do with the meat substitute product itself or with its role in a meal. They expressed motives about product characteristics of meat substitutes (captured in the categories Properties, Convenience and Nutrition), the role of the meat substitute in a meal (categories Functionality and Association with meals), specific preferences (Preferences) and direct relation to the meat counterpart (Association with meat).

Several motives in the category of Convenience were mentioned often. All products were mentioned to be "easy to prepare", especially in the situation "time scarcity", which was also one of the outcomes of previous focus groups (Elzerman et al., 2013). Especially the vegetarian hamburger was often mentioned combined with these motives, as also reflected in the previous survey, where both normal and vegetarian hamburgers rated high on appropriateness when cooking with time scarcity (Elzerman et al., 2021). According to another study, consumers grouped normal meat hamburgers and vegetarian hamburgers in the same product category (Hartmann and Siegrist, 2017). Furthermore, the four meat substitutes were also associated with being almost ready to eat, easy to store in the freezer and easy to divide into smaller portions, motives that also fell in the category of Convenience. Whether the convenience of a product is seen as a positive characteristic depends on the type of consumer. Bernués et al. (2012) distinguished four consumer segments regarding the convenience of lamb meat and showed that satisfaction derived from cooking, time spent on cooking, and preference for certain types of recipes were of different importance to the different segments. Although there is a market for convenient home cooking (Leroy and Degreef, 2015), the time that consumers wish to spend on cooking varies. This could imply that also for some of our participants, convenience had a merely positive meaning, whereas others might not be able to use their creativity in the preparation of a meal with meat substitutes.

In the category Properties, extrinsic product properties, such as price and portion size, as well as intrinsic properties, like taste and texture were captured. Although many studies concluded that the sensory appeal of meat substitutes is low and that the sensory properties should be improved (Weinrich, 2018; Fiorentini et al., 2020; Michel et al., 2021), a bad sensory appeal was not often mentioned as such in our study. However, e.g. "bland taste" and 
"preference for other vegetarian options" could also refer to the sensory properties of the products. Mainly for vegetarian steak and in the situations "when I have little time to cook", "eating alone" and "to add flavour to the meal", it was mentioned that the meat substitute was not liked well or was not tasty. An explanation for this could be that the vegetarian steak is a relatively new product and the counterpart of a steak, which is often seen as a high-end product of which the sensory properties are highly valued, which is in line with findings of Michel et al. (2021). Conversely, the other products (vegetarian hamburger, vegetarian mince and vegetarian stir-fry pieces) might have been more familiar to the participants. Familiarity is a predictor of the acceptance of plant-based meat substitutes (Bryant et al., 2019). Moreover, the mince and the stir-fry pieces are commonly used as an ingredient in a dish and therefore their sensory properties could be less important since those can be masked when eaten in a dish. Meal context has been shown to improve the acceptance of meat substitutes in a central location test (Elzerman et al., 2011).

Another explanation for the few hedonic associations that were mentioned could be that appropriateness questions elicit answers based more on cultural norms and less on liking (Giacalone and Jaeger, 2019). Consumers tend to focus on the fulfilment of the goals that are associated with a particular consumption situation, and not just on personal preferences and product characteristics (Giacalone and Jaeger, 2019). For some of the meat substitutes and usage situations in our study, other factors might have been more important in the situational appropriateness, like the following quote illustrates:

I would not buy meat substitutes when I'm cooking for myself. Maybe because of the price, meat substitutes are not really expensive, but they are not cheap either [participant 3]

Nutritional product properties were summarized in a separate category to get more insight into the nutritional and health considerations of the participants since health aspects are drivers of consumer acceptance of meat alternatives (as reviewed by Onwezen et al., 2021). Although health aspects were mentioned as associations with the more general question on "eating vegetarian", these aspects did not seem to be important drivers of the appropriateness of meat substitutes in all usage situations. Nutritional and health aspects seem to be important factors when cooking a healthy meal and were also mentioned when making dinner for the family (Table 2). Both negative and positive nutritional factors were mentioned, like in the following quotes:

Vegetarian steak and hamburger ... it is questionable how healthy those products are. Sodium, fat, artificial [participant 9]

I see them all as healthy. All good things of meat are in the meat substitutes, like proteins and I also think they added B-vitamins [participant 8]

Nutritional advantages and concerns regarding meat substitutes were also expressed during focus group discussions (Elzerman et al., 2013). Consumers seem to be unsure about the health benefits of meat substitutes (Onwezen et al., 2021).

The categories Functionality and Association with meals represented associations that participants made with specific recipes, meals or preparations (Functionality) or with the role the meal was taking in their diets (Association with meals). In the category Association with meals, participants mentioned the length or the healthiness of the meals. One of the participants mentioned:

I associate steak with extensive dinners, so, no, a vegetarian steak I would not use if I had little time to cook

In the category Functionality, most participants mentioned a specific dish when they were discussing the appropriateness of a meat substitute in a usage situation. This was mainly for 
BFJ

124,13

104

mince and stir-fry pieces, meat substitutes that can be used as an ingredient in a dish, as shown in this quote:

My mother sometimes makes "Chicken tikka masala." When I made it myself, I used vegetarian stirfry pieces instead, because without chicken it was a lonely sauce. [participant 5]

Other motives in this category were more general:

When you want to cook a nice "fancy" vegetarian dish, you are not going to use these things. Meat substitutes are more ordinary [participant 13]

Motives for the situation "when cooking something special" are mostly associated with particular types of meals (e.g. "product is associated with something special", "product is not associated with extensive dinners" and "product is associated with regular meals") (see Figure 2). Especially, vegetarian steak is associated with something special (see Figure 2a), although the big majority preferred the meat variant, as expressed by one of the participants:

I would not choose the vegetarian steak. If you want to eat something like a steak, you can better eat a real steak once a week and eat vegetarian for the rest of the week [participant 4]

These findings match with the results of our previous survey, where a normal steak received high appropriateness ratings for "cooking something special", and the vegetarian steak was perceived as much less appropriate (Elzerman et al., 2021).

Other motives in the category Preferences included the choice of other vegetarian options over meat substitutes:

When I want to eat a really healthy meal, I take beans and lentils [participant 9]

Besides expressed preferences, some participants compared the meat substitute to the meat variant when thinking about the situational appropriateness. These motives were summarized in a separate category, to get an idea of the importance of this comparison. Only a few of the respondents expressed such a comparison, by comparing the nutritional value or the appropriateness of the meat and meat substitutes, as stated in the following quote:

I think the normal hamburger would also be appropriate if you have little time to prepare your meal. I do not think the vegetarian variant needs more time to cook. [participant 5]

Surprisingly, most participants did not mention any comparison to the meat variant. This suggests that those participants considered meat substitutes as a product category by itself, and not just as substitutes for meat.

In the current exploratory study, we aimed to get a broad range of perspectives on meat substitutes and their situational appropriateness. The obtained results are of importance for the understanding of consumer acceptance of meat substitutes and can direct food companies in their development of new meat substitutes. For policymakers, the nutritional and environmental aspects of meat and meat substitutes could be further researched and communicated to consumers (Santo et al., 2020), and there is a role in the education of children to get them acquainted with meat alternatives since the parents' attitudes and attachment to meat seem to play a crucial role in children's meal choice (Erhardt and Olsen, 2021).

Our research has several limitations. The participants were comprised of both vegetarian and non-vegetarian respondents, to get a wide range of motives. We did not aim to compare these groups. Although data saturation was reached in our study, care should be taken when generalizing the results. To keep the interview feasible for the interviewees, four meat substitutes and six usage situations were used. Other products or situations could elicit maybe more motives. Furthermore, our participants were all Dutch and the generated 
associations and motives could differ from other countries/cultures. Cultural factors play a role in the perception of meat and insects (Schössler et al., 2015; Onwezen et al., 2021), so may also be of importance to the perceived appropriateness and acceptance of meat substitutes. Furthermore, only a few men participated in this study. Although men gave similar ratings and only sometimes slightly lower ratings in a previous study on situational appropriateness of meat substitutes (Elzerman et al., 2021), other studies underlined the importance of gender differences regarding meat, meat substitutes and vegetarianism (Trelohan, 2021; Rosenfeld and Tomiyama, 2021). Moreover, all participants were users of meat substitutes and therefore might have been more interested in meat substitutes. Possibly, they were among the "early adopters" or "early majority" that accepted meat substitutes, when looked at from the diffusion of innovation theory (Rogers, 2003). Knowing the motives and barriers of consumers that are more at the forefront of the innovation, the adoption curve could also help to understand consumers who are not yet ready to adopt meat substitutes (Gonera et al., 2021). The environmental issues involved with meat production are not yet considered as important drivers for the consumers who are reluctant to try meat substitutes and the possible environmental advantage of meat substitutes is not recognized by them. More visible benefits of meat substitutes should be promoted by marketers to win these consumers over (Szedja et al., 2020). Future research, such as a quantitative survey, could identify differences between motives of non-users and users of meat substitutes, different cultures, and could make use of more combinations of meat substitutes and usage situations that data could then be used as a basis for theory development of what factors play a role in the situational appropriateness of meat substitutes.

\section{Conclusions}

Eating vegetarian was associated with the omission of meat and with the environmental impact of meat production, health aspects and animal welfare. Meat substitutes were associated with nutrient substitution, preferences regarding the (dis)similarity to meat and specific meat substitutes. Consumer motives for the situational (in)appropriateness of meat substitutes can be grouped into several categories regarding the meat substitute product itself (categories Properties, Convenience and Nutrition), the role of the meat substitute in a meal (Functionality and Association with meals), specific preferences (Preferences) and direct relation to the meat counterpart (Association with meat). Easy and fast preparation were drivers of the situational appropriateness of all four meat substitutes and the mince and stir-fry pieces received mostly positive motives. Barriers for vegetarian steak and hamburger were the taste, preference for the meat variant, nutritional factors and the image of the product. Overall, meat substitutes fitted better in everyday eating situations and were less appropriate for special occasions. The current study suggests an image of meat substitutes as being processed, ordinary and convenient, which are useful insights for the research and development (R\&D) and marketing of plant-based meat substitutes. To convince more and other consumers, the focus might need a shift towards less processed products, with a more natural image and recipe ideas for more extensive cooking. Furthermore, there is a role for policymakers and education to get adults as well as children acquainted with the benefits and use of meat substitutes.

Whether it can be generalized that underlying motives behind appropriateness is contextspecific should be part of future research.

\section{References}

Aiking, H. (2011), "Future protein supply", Trends in Food Science and Technology, Vol. 22 Nos 2-3, pp. 112-120.

Use of meat substitutes 
BFJ

124,13

Bernués, A., Ripoll, G. and Panea, B. (2012), "Consumer segmentation based on convenience orientation and attitudes towards quality attributes of lamb meat”, Food Quality and Preference, Vol. 26, pp. 211-220, doi: 10.1016/j.foodqual.2012.04.008.

Bryant, C., Szejda, K., Parek, H N., Deshpande, V. and Tse, B. (2019), “A survey of consumer perceptions of plant-based and clean meat in the USA, India, and China”, Frontiers in Sustainable Food Systems, Vol. 3 No. 11, doi: 10.3389/fsufs.2019.00011.

Dagevos, H., Verhoog, D., van Horne, P. and Hoste, R. (2020), "Vleesconsumptie per hoofd van de bevolking in Nederland, 2005-2019”, Wageningen Economic Research, doi: 10.18174/531409.

De Bakker, E. and Dagevos, H. (2010), Vleesminnaars, vleesminderaars en vleesmïders: Duurzame eiwitconsumptie in een carnivore eetcultuur, [Meat lovers, meat reducers and meat avoiders: Sustainable protein consumption in a carnivorous food culture], LEI Wageningen UR, The Hague.

De Boer, J. and Aiking, H. (2017), "Pursuing a low meat diet to improve both health and sustainability: how can we use the frames that shape our meals?", Ecological Economics, Vol. 142, pp. 238-248.

De Waart (2021), “Trends in vleesvervangers”, De vegetariërsbond, available at: https://www. vegetariers.nl/lekker/magazine/historie/geschiedenis-van-vleesvervangers (accessed 12 September 2021).

Elzerman, J.E., Hoek, A.C., van Boekel, M.A.J.S. and Luning, P.A. (2011), "Consumer acceptance and appropriateness of meat substitutes in a meal context", Food Quality and Preference, Vol. 22, pp. 233-240.

Elzerman, J.E., van Boekel, M.A.J.S. and Luning, P.A. (2013), "Exploring meat substitutes: consumer experiences and contextual factors", British Food Journal, Vol. 115 No. 5, pp. 700-710.

Elzerman, J.E., Keulemans, L., Sap, R. and Luning, P.A. (2021), "Situational appropriateness of meat products, meat substitutes and meat alternatives as perceived by Dutch consumers", Food Quality and Preference, Vol. 88, p. 104108, doi: 10.1016/j.foodqual.2020.104108.

Erhardt, J. and Olsen, A. (2021), "Meat Reduction in 5 to 8 Years Old Children-a Survey to investigate the role of parental meat attachment”, Foods, Vol. 10, p. 1756, doi: 10.3390/ foods10081756.

Fiorentini, M., Kinchla, A.J. and Nolden, A.A. (2020), "Role of sensory evaluation in consumer acceptance of plant-based meat analogs and meat extenders: a scoping review", Foods, Vol. 9 No. 9, p. 1334, MDPI AG, doi: 10.3390/foods9091334.

Giacalone, D. and Jaeger, S.R. (2019), "Perceived situational appropriateness as a predictor of consumers' food and beverage choices", Frontiers in Psychology, Vol. 10, p. 1743, doi: 10.3389/ fpsyg.2019.01743.

Gonera, A., Svanes, E., Bugge, A., Hatlebakk, M., Prexl, K. and Ueland, Ø. (2021), "Moving consumers along the innovation adoption curve: a new approach to accelerate the shift toward a more sustainable diet", Sustainability, Vol. 13, doi: 10.3390/su13084477.

Guest, G., Bunce, A. and Johnson, L. (2006), "How many interviews are enough? An experiment with data saturation and variability", Field Methods, Vol. 18 No. 10, pp. 59-82.

Hartmann, C. and Siegrist, M. (2017), "Consumer perception and behaviour regarding sustainable protein consumption: a systematic review", Trends in Food Science and Technology, Vol. 61, pp. 11-25.

Hersleth, M., Monteleone, E., Segtnan, A. and Naes, T. (2015), "Effects of evoked meal contexts on consumers' responses to intrinsic and extrinsic product attributes in dry-cured ham", Food Quality and Preference, Vol. 40, pp. 191-198.

Higgs, S. (2015), "Social norms and their influence on eating behaviors", Appetite, Vol. 86, pp. 38-44.

Hoek, A.C., Luning, P.A., Weijzen, P., Engels, W., Kok, F.J. and de Graaf, C. (2011a), "Replacement of meat by meat substitutes. A survey on person- and product-related factors in consumer acceptance", Appetite, Vol. 56, pp. 662-673. 
Hoek, A.C., van Boekel, M.A.J.S., Voordouw, J. and Luning, P.A. (2011b), "Identification of new food alternatives: how do consumers categorize meat and meat substitutes?", Food Quality and Preference, Vol. 22, pp. 371-383.

Hoek, A.C., Elzerman, J.E., Hageman, R., Kok, F., Luning, P.A. and de Graaf, C. (2013), "Are meat substitutes liked better over time? A repeated in-home use test with meat substitutes or meat in meals", Food Quality and Preference, Vol. 28, pp. 253-263.

Horvat, A., Fogliano, V. and Luning, P.A. (2020), "Modifying the Bass diffusion model to study adoption of radical new foods-The case of edible insects in The Netherlands", PLoS ONE, Vol. 15 No. 6, e0234538.

IRI Nederland (2021), "Kwartaalupdate Q1 2021, De huidige status van de eiwittransitie in de NL supermarkt”, PowerPoint Presentation, IRI Market research.

Leroy, F. and Degreef, F. (2015), "Convenient meat and meat products. Societal and technological issues”, Appetite, Vol. 94, pp. 40-46.

Michel, F., Hartmann, C. and Siegrist, M. (2021), "Consumers' associations, perceptions and acceptance of meat and plant based meat alternatives", Food Quality and Preference, Vol. 87.

Mullee, A., Vermeire, L., Vanaelst, B., Mullie, P., Deriemaeker, P., Leenaert, T., De Henauw, S., Dunne, A., Gunter, M.J., Clarys, P. and Huybrechts, I. (2017), "Vegetarianism and meat consumption: a comparison of attitudes and beliefs between vegetarian, semi-vegetarian, and omnivorous subjects in Belgium”, Appetite, Vol. 114, pp. 299-305, doi: 10.1016/j.appet.2017.03.052.

Onwezen, M.C., Bouwman, E.P., Reinders, M.J. and Dagevos, H. (2021), "A systematic review on consumer acceptance of alternative proteins: pulses, algae, insects, plant-based meat alternatives, and cultured meat", Appetite, Vol. 159, p. 105058.

Rogers, E.M. (2003), Diffusion of Innovations, 5th ed., Simon and Schuster Free Press, New York, NY, 2003.

Rosenfeld, D.L. and Tomiyama, A.J. (2021), "Gender differences in meat consumption and openness to vegetarianism”, Appetite, Vol. 166, doi: 10.1016/j.appet.2021.105475.

Sanchez-Sabate, R. and Sabaté, J. (2019), "Consumer attitudes towards environmental concerns of meat consumption: a systematic review", International Journal of Environmental Research and Public Health, Vol. 16 No. 7, p. 1220, doi: 10.3390/ijerph16071220.

Santo, R.E., Kim, B.F., Goldman, S.E., Dutkiewicz, J., Biehl, E.M.B., Bloem, M.W., Neff, R.A. and Nachman, K.E. (2020), "Considering plant-based meat substitutes and cell-based meats: a public health and food systems perspective", Frontiers in Sustainable Food Systems, Vol. 4, p. 134, doi: 10.3389/fsufs.2020.00134.

Schösler, H., de Boer, J., Boersema, J. and Aiking, H. (2015), "Meat and masculinity among young Chinese, Turkish and Dutch adults in The Netherlands", Appetite, Vol. 89, pp. 152-159.

Schutz, H.G. (1988), "Beyond preference: appropriateness as a measure of contextual evaluation of food", in Thomson, D.M.H. (Ed.), Food Acceptability, Elsevier Applied Science, London, pp. 115-134.

Smil, V. (2002), "Worldwide transformation of diets, burdens of meat production and opportunities for novel food proteins”, Enzyme and Microbial Technology, Vol. 30 No. 1, pp. 305-311.

Szejda, K., Urbanovich, T. and Wilks, M. (2020), Accelerating Consumer Adoption of Plant-Based Meat: an Evidence-Based Guide for Effective Practice, Five Working Papers, The Good Food Institute, Washington, DC, available at: go.gfi.org/plant-based-meat-consumer-adoption.

Tijhuis, M.J., Ezendam, J., Westenbrink, S., van Rossum, C. and Temme, L. (2011), "Replacement of meat and dairy by more sustainable protein sources in The Netherlands - quality of the diet", RIVM Letter Report 350123001/2011.

Trelohan, M. (2021), "Do women engage in pro-environmental behaviours in the public sphere due to social expectations? The effects of social norm-based persuasive messages", VOLUNTAS: International Journal of Voluntary and Nonprofit Organizations. doi: 10.1007/s11266-02000303-9. 
BFJ

124,13

Tso, R., Lim, A.J. and Forde, C.G. (2021), "A critical appraisal of the evidence supporting consumer motivations for alternative proteins", Foods, Vol. 10, p. 24, doi: 10.3390/foods10010024.

Van der Weele, C., Feindt, P., van der Goot, A.J., van Mierlo, B. and Van Boekel, M. (2019), "Meat alternatives: an integrated comparison", Trends in Food Science and Technology, Vol. 88, pp. 505-512, doi: 10.1016/j.tifs.2019.04.018.

Van Loo, E., Hoefkens, C. and Verbeke, W. (2017), "Healthy, sustainable and plant-based eating: perceived (mis)match and involvement-based consumer segments as targets for future policy", Food Policy, Vol. 69 No. issue C, pp. 46-57.

VERBI Software (2019), MAXQDA 2020 (Computer Software), VERBI Software, Berlin, available from: maxqda.com.

Weinrich, R. (2018), "Cross-cultural comparison between German, French and Dutch consumer preferences for meat substitutes", Sustainability, Vol. 10 No. 6, p. 1819, doi: 10.3390/su10061819.

Willett, W., Rockström, J., Loken, B., Springmann, M., Lang, T., Vermeulen, S., Garnett, T., Tilman, D., DeClerck, F., Wood, A., Jonell, M., Clarck, M., Gordon, L.J., Fanzo, J., Hawkes, C., Zurayk, R., Rivera, J.A., De Vries, W., Majele Sibanda, L., Afshin, A., Chaudhary, C., Herroro, M., Agustina, R., Branca, F., Lartey, A., Fan, S., Crona, B., Fox, E., Bignet, V., Troell, M., Lindahl, T., Singh, S., Cornell, S.E., Reddy, K.S., Narain, S., Nishtar, S. and Murray, J.D. (2019), "Food in the Anthropocene: the EAT-Lancet Commission on healthy diets from sustainable food systems", Lancet, Vol. 393 No. 10170, pp. 447-492, available at: https://www.ncbi.nlm.nih.gov/pubmed/ 30660336 .

Zanin, L.A., Luning, P.A., da Cunha, D.T. and Stedefeldt, E. (2021), "Influence of educational actions on transitioning of food safety culture in a food service context: part 1 - triangulation and data interpretation of food safety culture elements", Food Control, Vol. 119, p. 107447.

\section{Appendix}

The supplemental material available online for this article.

\section{Corresponding author}

Johanna E. Elzerman can be contacted at: hanneke.elzerman@hvhl.nl

For instructions on how to order reprints of this article, please visit our website:

www.emeraldgrouppublishing.com/licensing/reprints.htm

Or contact us for further details: permissions@emeraldinsight.com 